\title{
Energy access is needed to maintain health during pandemics
}

\author{
Energy plays a central role in responding to emergencies such as the COVID-19 pandemic, from ensuring adequate \\ healthcare services to supporting households during lockdowns. Protecting the renewable energy industry and its \\ contribution to providing sustainable energy access for all must be an urgent priority in the current crisis.
}

\section{Vanesa Castán Broto and Joshua Kirshner}

E nergy access is recognized both as a pillar of international cooperation and as an intractable problem. Sustainable Development Goal 7 (SDG 7) commits to ensuring "access to affordable, reliable, sustainable, and modern energy for all". Progress so far has not matched these expectations. According to United Nations data, the global electrification rate reached $89 \%$ in 2017 , up from $83 \%$ in $2010^{1}$. The global share of the population with access to clean cooking fuels and technologies was $61 \%$ in 2017 , up from $57 \%$ in $2010^{1}$. However, there are still 840 million people in the world without access to electricity. Almost 3 billion people rely on inefficient and polluting cooking fuels and technologies ${ }^{1}$. While there has been enormous progress towards facilitating energy access in large countries such as China and Indonesia, there are some regions in which progress has been meagre, particularly countries in sub-Saharan Africa, parts of Asia and countries suffering protracted conflicts, such as Syria and Yemen.

Energy access matters more than ever in the time of COVID-19. First, energy access is closely linked to our ability to respond to the pandemic. In particular, energy is key to health care services. Second, the nationwide lockdown measures currently affecting numerous countries and regions across the world will impact disproportionately those who already struggle with energy access. Third, COVID-19 will influence the delivery of sustainable energy access, as flows of finance and technology depend on a globally interconnected world that no longer seems practicable.

\section{Energy and health services}

Insufficient energy access quickens the spread of COVID-19 while hampering global efforts to contain it. The most widely used everyday measures for slowing the COVID-19 contagion are especially challenging for the poor majority lacking

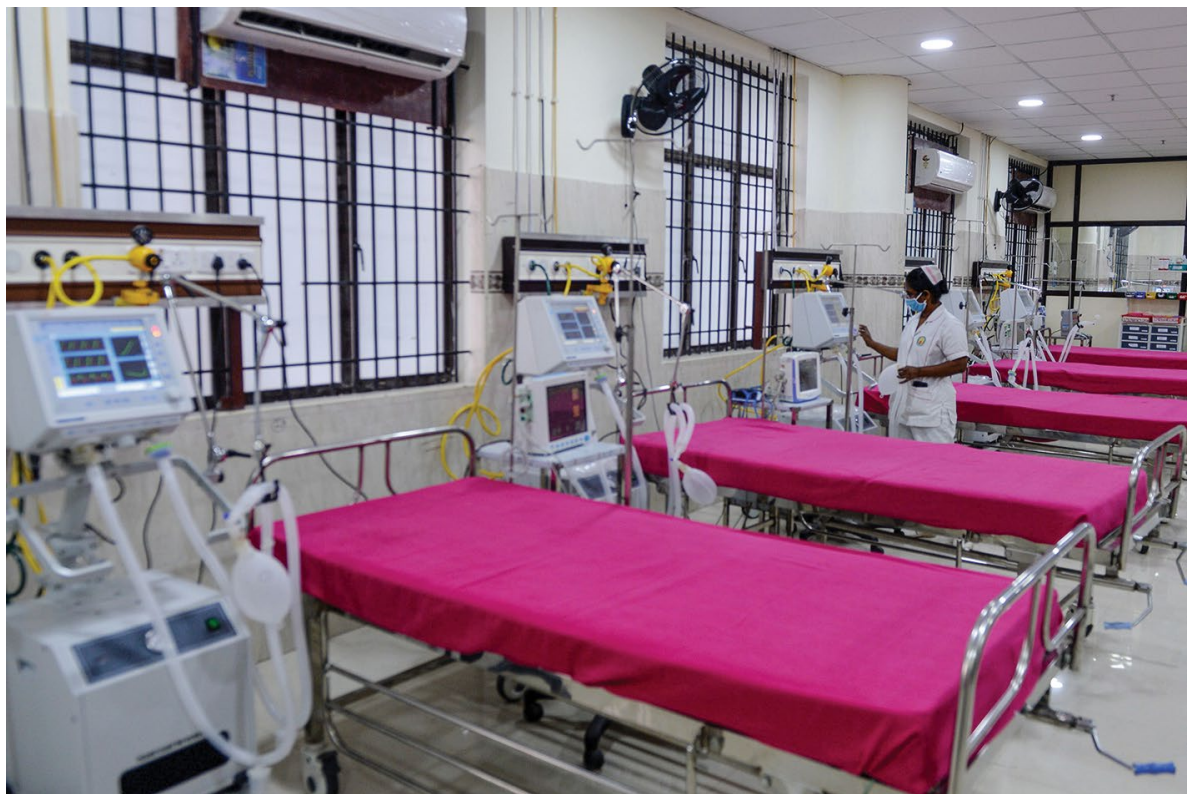

A member of medical staff checks on a ventilator in an intensive care unit at a hospital newly inaugurated by the Tamil Nadu state during a government-imposed nationwide lockdown implemented as a preventive measure against COVID-19 - in Chennai on 27 March 2020. Credit: ARUN SANKAR/AFP via Getty Images

access to essential energy services ${ }^{2}$. A seemingly simple action such as handwashing can be extremely complicated for families for whom heating water comes at a high cost.

Households without energy access face health risks embedded in daily practices that may exacerbate COVID-19 symptoms ${ }^{3}$. Daily exposures to indoor pollution remain a significant determinant of health risks in countries with low rates of energy access ${ }^{4}$. Indoor pollution from burning solid carbon based fuels such as charcoal, wood, peat or lignite is directly linked to multiple respiratory conditions ${ }^{5}$. There is some evidence of exposure to atmospheric air pollution as a risk factor for COVID-196,7, but research on indoor air pollution is lagging.
Energy access is also a critical enabler of health care delivery and access to medical technologies ${ }^{8}$. While hospitals in developed economies struggle to provide medical resources to populations under growing strain from COVID-19, hospitals and health facilities in low- and middle-income countries face the pandemic alongside the continuous infrastructure and energy access challenges that precede it ${ }^{9}$.

Health facilities have two main energy requirements: electricity for health services and medical equipment, and thermal requirements related to sterilization, space and water heating, and incineration ${ }^{10}$. Without access to reliable electricity, health workers must carry out work in near darkness, relying on kerosene lanterns, candles and mobile phones. Vaccines and 
medications needing refrigeration cannot be stored, and medical equipment and devices cannot be sterilized or used at all ${ }^{11}$.

Lack of energy access poses additional challenges for the provision of emergency care services and the functioning of intensive care units ${ }^{12}$. The ventilator has become a symbol of the kind of intensive care response that this pandemic requires, one that necessitates electricity. A prompt emergency response also depends on reliable energy access. In a pandemic, the additional demands to deal with patients as rapidly as possible and to facilitate communication pose a further strain on already compromised systems. When basic energy services are unavailable, essential components of emergency responses become compromised, including night-time care, refrigeration to keep samples, sterilization facilities or electricity to power simple medical devices ${ }^{8}$.

A comparative study of environmental conditions in health facilities compared 46 middle and low-income countries, finding that $59 \%$ of all health facilities lacked access to electricity ${ }^{13}$. In rural India, Rural Health Statistics used 2018 data to show that nearly 40,000 government-run health facilities, serving some 580 million people, were operating without an electricity supply.

Even if there is a supply of electricity, power failures and outages may compromise health care provision. Many facilities in lower income countries depend on back-up diesel generators, which are expensive, unreliable, inefficient, noisy and dirty ${ }^{8}$. A study of 480 health facilities in Senegal found that, in a context in which less than half of the facilities (48\%) had access to electricity, $18 \%$ of facilities and $3 \%$ of hospitals relied on generators or solar systems as the sole source of electricity ${ }^{14}$.

There has been a growing interest on the potential for solar photovoltaics to complement grid access ${ }^{15}$ in countries such as Uganda (where 15\% of hospitals already use solar energy) and Sierra Leone (where $36 \%$ of health facilities and $46 \%$ of hospitals combine solar photovoltaics with other forms of energy). Research has also demonstrated the potential of hybrid solar systems to provide reliable energy in health settings ${ }^{16}$. However, obstacles such as high capital costs, limited forms of alternative finance and requirements for equipment maintenance limit the development of renewable energy for health facilities ${ }^{8}$.

\section{Life under lockdown}

Enforced social distancing and lockdowns rest on the assumption that populations have energy access, including fuels for cooking and thermal comfort, and electricity for lighting and remote communications. In the US, for example, the assumption is that the lockdown will increase the energy consumption in households because being at home requires more energy being spent domestically. In countries with low rates of energy access, many households may not be able to increase energy consumption to supply additional needs. Factors such as aversion to risks related to the fluctuation of energy prices and capacity to invest in new energy-consuming appliances may limit households' consumption ${ }^{17}$.

In India, the sudden onset of the lockdown made it impossible for households to prepare for $\mathrm{it}^{18}$, for example, by storing sufficient fuel. Many people lack a safe space with access to vital goods and services, including maintaining their physical surroundings at comfortable temperatures, cooking food and ensuring the availability of enough fuel and water to maintain life. Access to fuel, in particular, may be an insurmountable challenge during lockdown for people who buy it at neighbourhood street markets ${ }^{3,19}$. Small traders enable households to buy essential goods in small amounts that households can afford ${ }^{20}$. This is particularly important for the provision of fuels in urban markets, where small traders enable households to buy just enough fuel to pass the day ${ }^{21}$.

Extended lockdown and quarantine measures imposed by states to contain the spread of COVID-19 also tend to assume the availability of energy for essential communications, ranging from social interactions to business transactions. Yet, for communities without energy access, such communications become difficult. Research has demonstrated that energy access fosters expanded communications and wider local and regional development strategies. Access to mobile phones improves educational outcomes, mental health, political engagement and social capital among the poorest people, including better integration of family networks, improved contact with business and public services, supply chains and financial organizations (and participation in the marketplace through mobile banking and money transfer using smartphone apps and telephone banking) ${ }^{22}$.

The reduced cost of mediated communications, such as through electrical telecommunications infrastructure, leads to tangible economic benefits, improving agricultural and labour market efficiency, producer and consumer welfare, access to media content and wider rural connectivity, as noted in a study of rural Zambia ${ }^{23}$. Lack of energy access underpinning these forms of connectivity is particularly harmful during a pandemic and can be compounded by additional environmental stressors, civil unrest or market changes.

Finally, lack of energy access also translates into reduced mobility. The lockdown has curtailed the availability of public transport and made it difficult for people to access vehicles and fuels. Transport may be essential for farmers who need to bring their produce to markets, for migrant labourers who need to return home for the lockdown or for anyone who needs to travel to health clinics for emergency care from areas without them.

In India, a massive exodus of informal workers who wanted to reach their native villages took place between 27 March and 30 March 2020. A study compiling published data on deaths by the press recorded 32 deaths due to some of these workers being run over by trucks and other vehicles, and 20 deaths due to exhaustion and hunger of workers that attempted to walk hundreds of kilometres to reach their villages ${ }^{18}$. Informal transport is a gap filler for many families that can only meet their mobility needs that way, but this is compromised under lockdown. Migrant workers remain stranded in countries such as Myanmar and Nepal ${ }^{24}$. Profound inequalities in energy access have become visible under COVID-19, because of the urgent need to access the means of production, a safe home and rapid mobility.

\section{Energy access after COVID-19}

The coronavirus crisis is mutating into a humanitarian and an economic crisis, in which some sectors, particularly energy, are severely affected. The consequences are unpredictable. Electricity demand appears to have declined in economies that have taken strong confinement measures, especially due to the closure of factories and businesses ${ }^{25}$. Demand and prices for oil and gas is collapsing in China, the US and the Eurozone, while global supply chains and flows of foreign direct investment in energy resources have been disrupted ${ }^{26}$.

International financial flows into developing countries in support of clean and renewable energy reached US $\$ 18.6$ billion in 2016, almost doubling from US\$9.9 billion in $2010^{1}$. Both the International Energy Agency (IEA) and the International Renewable Energy Agency (IRENA) have called for maintaining renewable energy investments in the wake of COVID-1925,27. There are also hints that the crisis may constitute an opportunity to increase the global share of renewables. The advantages of renewables, particularly in off-grid contexts and responding to the need to support the operation of health facilities, have become evident during the pandemic. Industry reports suggest that analysts within 
the renewable energy industry expect the sector to grow while fossil fuel-based industries will likely struggle financially ${ }^{28}$.

However, this positive outlook seems to overlook the precarious state of important sections of the renewable energy industry and whether it is flexible enough to deal with the pandemic. The renewable energy industry is not immune to the coronavirus. There have already been impacts because of the disruption to supply chains, particularly for providers relying on manufacturers in China and Southeast Asia ${ }^{29}$. A survey from the global association for the off-grid solar energy sector (GOGLA) found that GOGLA members have encountered important challenges to operations, and disruptions in sales and after-sales support due to the COVID-19 pandemic. About $11 \%$ of GOGLA members have found themselves in immediate financial trouble, while $46 \%$ will be in financial trouble if the crisis lasts more than three or four month $s^{30}$. The collapse of these renewable energy companies, many of whom operate in vulnerable communities, will have direct consequences for those who depend on them and who may find themselves facing dire conditions for energy access.

International cooperation on sustainable energy access, especially in the past decade, has made great progress in advancing SDG 7. While the crisis has exposed some limitations (for example, the need to increase investment in energy in health facilities $^{8}$ ), the question is whether the COVID-19 crisis will transform the international cooperation landscape and what the consequences will be for those facing energy poverty.

In the near term, if investment is maintained, local professionals could replace international consultants and develop endogenous energy industries to bring the world closer to delivering clean energy for all. In the long term, we need further research on the relationship between health and energy access, and how sweeping measures taken during a pandemic, such as mandated lockdowns, affect the most vulnerable populations.

Much will be lost if donor priorities shift away from energy access. As a research community, we need to reiterate the centrality of energy access to promote and maintain health, avoid respiratory illnesses, and support an operational and responsive health service. Maintaining health under pandemics, such as COVID-19, depends on people's ability to access energy independently and reliably.

\section{Vanesa Castán Broto (D) ${ }^{1 凶}$ and Joshua Kirshner (D)2}

${ }^{1}$ Urban Institute, University of Sheffield, Sheffield, UK. ${ }^{2}$ Department of Environment and Geography, University of York, York, UK.

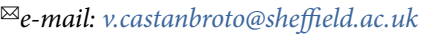

Published online: 11 May 2020

https://doi.org/10.1038/s41560-020-0625-6

References

1. UN Secretary-General. Special Edition: Progress Towards the Sustainable Development Goals (UN Economic and Social Council, 2019).

2. Ogunbiyi, D. Here's why energy security is a vital tool in tackling a pandemic. World Economic Forum https://www.weforum.org/ agenda/2020/04/pandemic-energy-access-coronavirus (2020).

3. Schiffer, A. Reframing Energy Access: Insights from The Gambia (Routledge, 2020).

4. Zaman, K., Ahmad, A., Hamzah, T. A. A. T. \& Yusoff, M. M. Soc. Indic. Res. 129, 215-228 (2016).

5. Fullerton, D. G., Bruce, N. \& Gordon, S. B. Trans. R. Soc. Trop. Med. Hyg. 102, 843-851 (2008).

6. Wu, X., Nethery, R. C., Sabath, B. M., Braun, D. \& Dominici, F. Preprint at medRxiv https://doi.org/10.1101/2020.04.05.20054502 (2020).

7. Conticini, E., Frediani, B. \& Caro, D. Environ. Pollut. https://doi. org/10.1016/j.envpol.2020.114465 (2020).

8. Access to Modern Energy Services for Health Facilities in Resource-Constrained Settings: A Review of Status, Significance, Challenges and Measurement (World Health Organization, 2015)

9. Kibiti, B. \& Stachel, L. Coronavirus is not the only global health crisis. Just ask $1 \frac{12}{2}$ billion people. Sustainable Energy for All https://www.seforall.org/news/ coronavirus-is-not-the-only-global-health-crisis (2020).

10. Suhlrie, L. et al. PLoS One 13, e0200261-e0200261 (2018)
11. Roth, S. \& Silva, F. 3 ways investing in energy makes people healthier. Asian Development Blog https://blogs.adb.org/blog/3-wa ys-investing-energy-makes-people-healthier (2020).

12. Stafford, R. E., Morrison, C. A., Godfrey, G. \& Mahalu, W. Glob. Heart 9, 319-323 (2014).

13. Cronk, R. \& Bartram, J. Int. J. Hyg. Environ. Health 221, 409-422 (2018)

14. Ouedraogo, N. S. \& Schimanski, C. J. Public Health Policy 39, 358-371 (2018).

15. Dholakia, H. H. Nat. Energy 3, 705-707 (2018).

16. Olatomiwa, L., Blanchard, R., Mekhilef, S. \& Akinyele, D. Sustain Energy Technol. Assess. 30, 121-138 (2018).

17. Castán Broto, V. et al. Nat. Energy 2, 776-779 (2017).

18. Rawal, V., Manickem, K. A. \& Rawal, V. Are distress deaths necessary collateral damage of Covid-19 response? International Development Economic Associates http:// www.networkideas.org/featured-themes/2020/04/ are-distress-deaths-necessary-collateral-damage-of-covid19-response-the-experience-of-first-three-weeks-of-the-lockd own-in-india/ (2020).

19. Munro, P., van der Horst, G. \& Healy, S. Energy Policy 105, 635-641 (2017).

20. Kazeem, Y., Wadekar, N., Asiedu, K. G., Young, N. \& Matiashe, F. S. Across Africa, a reliance on the informal sector threatens effective coronavirus lockdowns. Quartz Africa https://qz.com/ africa/1831785/coronavirus-citizens-in

africas-informal-economy-try-to-survive/ (2020).

21. Castán Broto, V. Internation. Dev. Plan. Rev. 39, 229-248 (2017).

22. Sife, A. S., Kiondo, E. \& Lyimo-Macha, J. G. Electron. J. Inf. Syst. Dev. Ctries 42, 1-15 (2010).

23. Parks, L. Convergence 22, 440-460 (2016).

24. COVID-19: What Are Community Groups in Asia Already Doing? (Asian Coalition for Housing Rights, 2020); http://www.achr.net/ news-detail.php?id $=40$

25. Birol, F. The coronavirus crisis reminds us that electricity is more indispensable than ever. International Energy Agency https://www. iea.org/commentaries/the-coronavirus-crisis-

reminds-us-that-electricity-is-more-indispensable-than-ever (2020).

26. Jayaram, K., Leke, A., Ooko-Ombaka, A. \& Sun, Y. S. Tackling COVID-19 in Africa. McKinsey and Company https://www. mckinsey.com/featured-insights/middle-east-and-africa/ tackling-covid-19-in-africa (2020).

27. Camera, F. L. Staying on course: renewable energy in the time of COVID-19. International Renewable Energy Agency https://www.irena.org/newsroom/pressreleases/2020/Apr/ Staying-on-Course-Renewable-Energy-in-the-time-of-COVID19 (2020).

28. Penn, I. Oil companies are collapsing, but wind and solar energy keep growing. The New York Times (7 April 2020); https:// www.nytimes.com/2020/04/07/business/energy-environment/ coronavirus-oil-wind-solar-energy.html

29. Uetz, A. M. \& Miller, V. L. Managing the commercial impact of the coronavirus: Implications for the energy industry. The National Law Review https://www.natlawreview.com/article/ managing-commercial-impact-

coronavirus-implications-energy-industry (2020).

30. COVID-19: Coordinating an Industry Response for the Off-Grid Solar Sector (GOGLA, 2020). 